\title{
Influence of Body Mass Index (BMI), Age and Gender on Stages of Varicose Vein in Newly Diagnosed Cases Following Screening Doppler in Outpatient Clinic \\ Shrestha B, Karmacharya RM
}

Department of Surgery,

Kathmandu University School of Medical Sciences Dhulikhel, Kavre, Nepal.

\section{Corresponding Author}

Bikesh Shrestha

Department of Surgery,

Kathmandu University School of Medical Sciences Dhulikhel, Kavre, Nepal.

E-mail: bikeshsht@gmail.com

\section{Citation}

Shrestha B, Karmacharya RM. Influence of Body Mass Index (BMI), Age and Gender on Stages of Varicose Vein in Newly Diagnosed Cases Following Screening Doppler in Outpatient Clinic. Kathmandu Univ Med J. 2020;69(1):28-31.

\section{ABSTRACT}

\section{Background}

Varicose vein is one of the most common venous diseases which affect superficial veins especially of lower limb. This disease is characterized by prominent dilated veins, feeling of heaviness, itchiness, pigmentation, ulceration depending upon the stage of the disease.

\section{Objective}

This study was conducted to know how Body Mass Index, Age and Gender influence staging of varicose veins in our context.

\section{Method}

This is a cross sectional hospital based study conducted at Dhulikhel Hospital, Kathmandu University Hospital from April 2018 to March 2019. Patients with signs and symptoms of varicose vein were included in the study. Informed consent was taken from each patient and data collection done by filling the proforma.

\section{Result}

This study comprised 135 lower limbs with varicose vein from 108 patients. Male:Female ratio was 1.4:1. Mean age of patients was $44.47 \pm 12.65$ (17-81) years. Significant correlation was found between increasing age and progression in Clinical staging of Varicose vein according to Clinical classification $(p<0.05)$. Mean Great Saphenous Vein diameter at knee was found significantly higher in patients with more than five years of symptoms Mean Body Mass Index was not very different in different Clinical stage of Varicose veins.

\section{Conclusion}

This study showed that the Clinical Staging of Clinical Etiological Anatomical and Pathophysiological classification of varicose vein is significantly related to age. The mean diameter of Great Saphenous Vein at the level of Knee is significantly related to the duration of symptoms. However, the influence of Body Mass Index and gender on stages of varicose vein could not be established.

\section{KEY WORDS}

Age, Body mass index, Doppler, Gender, Varicose veins 


\section{INTRODUCTION}

Varicose vein is one of the most common venous diseases affecting superficial veins especially of lower limb. This disease is characterized by prominent dilated veins, feeling of heaviness, itchiness, pigmentation, ulceration depending upon the stage of the disease. ${ }^{1,2}$ Clinical Etiological Anatomical and Pathophysiological classification (CEAP) is used to categorize varicose veins. ${ }^{3}$

Obesity, age, parity, standing for long times, and family history are important risk factors for varicose veins. ${ }^{4}$ Incidence of varicose veins in adult population varies between $10 \%$ and $60 \%$ and the incidence increases linearly with age. ${ }^{4}$ Obesity has been suggested as one of the factor for development of varicose veins. ${ }^{5-8}$ Prevalence of varicose vein is more in female with prevalence as high as $40 \%$, compared to that in male of about $17 \%{ }^{9}$

Valve incompetence in superficial, perforating, or deep veins, obstruction of the deep venous system, and insufficiency of the calf muscle pump are characteristic features of Chronic venous disease (CVD). ${ }^{10}$ Clinical assessment of severity, quantification of hemodynamic effects, and identification of anatomic distribution is vital for further management of those patients. ${ }^{11}$ Duplex ultrasound scanning is considered the gold standard for the assessment of venous reflux because anatomical and functional hemodynamics can identify incompetent vein segments. ${ }^{12}$

Study comparing BMI and varicose vein severity is lacking in our context. Our aim was to know the influence of $\mathrm{BMI}$, age and gender on severity of varicose vein in newly diagnosed cases of varicose vein with use of outpatient doppler screening.

\section{METHODS}

This was a prospective cross sectional hospital based study conducted at the Outpatient Clinic of Department of Surgery at Dhulikhel Hospital, Kathmandu University Hospital from April 2018 to March 2019, after approval of institutional review committee. One hundred twenty seven sample size was calculated with estimated prevalence of $5 \%$ with $99 \%$ confidence interval. A total of 135 lower limb with varicose vein of 108 consecutive patients presenting to outpatient clinic with signs and symptoms of varicose vein within the study period were included in the study. Informed consent was taken from each patient and data collection done by filling the proforma. All patients aged $>18$ years and willing to participate in the study with signs and symptoms of varicose vein were included. Pregnant ladies, patients with past surgical intervention for varicose vein and those with DVT at the time of study were excluded from the study. Siemens ultrasound machine was used for quantification of varicose veins in terms of size of varicose vein and severity of reflux. Reflux in superficial veins was defined as retrograde flow if reflux time was greater than 500 milliseconds. Body Mass Index (BMI) was calculated as Weight (Kg)/Height (M)².

SPSS 20.0 (SPSS Inc., Chicago, IL, USA) was used for data analysis. Frequency analysis was done for scalar and ordinal variables. For nominal variables, descriptive analysis was performed with calculation of mean, range, standard deviation. Independent sample t-test was used for comparison of parametric scalar variables between two groups. For non-parametric categorical variables, Chi square test was used. The $p$ value of less than 0.05 was considered significant.

\section{RESULTS}

This study comprised 135 lower limbs with varicose vein from 108 patients, including 27 patients with bilateral lower limbs involvement. Among 108 patients, 63 were male and 45 were female patients. The average age of patients was $44.47 \pm 12.65$ years, ranging from 17 to 81 years. There was no statistically significant difference in age of male (45.23 \pm 13.24 years) and female patients $(43.40 \pm 11.85$ years $)$ ( $p>0.05)$.

The average BMI of patients was $25.42 \pm 4.42 \mathrm{~kg} / \mathrm{m}^{2}$. There was no statistically significant difference in average BMI of male $\left(25.00 \pm 4.66 \mathrm{~kg} / \mathrm{m}^{2}\right)$ and female patients $(26.01 \pm$ $\left.4.04 \mathrm{~kg} / \mathrm{m}^{2}\right) .(p>0.05)$.

The average duration of symptoms was $5.79 \pm 6.69$ years, ( 0.20 to 40.00 years). The average standing hours per day was $8.10 \pm 2.24$ hours, ( 4 to 14 hours).

Right leg was involved in 34 patients, left leg in 47 patients and 27 patients had both legs involvement. Prominent vein, feeling of heaviness and leg pain were the most frequent complains (table 1).

Table 1. Distribution of patients according to symptoms.

\begin{tabular}{ll|}
\hline Symptoms & Patients $\mathbf{n}(\%)$ \\
\hline Prominent veins & $127(94)$ \\
\hline Feeling of heaviness & $81(60)$ \\
\hline Leg pain & $73(54)$ \\
\hline Itchiness & $42(31)$ \\
\hline Pigmentation & $30(22)$ \\
\hline Ulceration & $08(6)$ \\
\hline
\end{tabular}

According to the CEAP classification, majority of cases were in C2 group (63\%), followed by C4 group (16.3\%) (table 2). 130 were primary varicose vein, while 5 cases were of secondary varicose vein.

Involvement of Great Saphenous Vein (GSV) was seen in $77 \%$, Short Saphenous Vein (SSV) in $16.3 \%$ and both system in $6.7 \%$. Among the limbs with GSV and both GSV and SSV venous system involvement, average Saphenofemoral 
Table 2. Distribution of patients according to Clinical appearance (C) of CEAP Classification.

\begin{tabular}{|ll|}
\hline Clinical Appearance(C) & Limbs $\mathbf{n}(\%)$ \\
\hline Normal (C0) & $1(0.7)$ \\
\hline Varicosities (C1) & $13(9.6)$ \\
\hline Varicose vein (C2) & $85(63)$ \\
\hline Edema (C3) & $7(5.2)$ \\
\hline Pigmentation (C4) & $22(16.3)$ \\
\hline Healed Venous Ulcer (C5) & $3(2.2)$ \\
\hline Active Venous Ulcer (C6) & $4(3)$ \\
\hline
\end{tabular}

junction (SFJ) diameter was 7.57 $\pm 1.76 \mathrm{~mm}$ (3.80-14.00), GSV diameter at knee level was $6.57 \pm 2.83 \mathrm{~mm}$ (2.50$18.00)$ and average time of reflux at SFJ was $717.86 \pm 352$ ms (70-1850).

In $98.51 \%$ the cause of varicose veins was reflux, either from junction and/or perforators. In two patients obstruction was the cause.

Mean age was highest in C4 stage (53.09 years) and lowest in $\mathrm{C} 1$ stage (40.23 years). (Table 3 )

Table 3. Mean age of patients according to clinical appearance (C) of CEAP Classification.

\begin{tabular}{|lll|}
\hline Clinical Appearance (C) & Mean age (Years) & P value \\
\hline Varicosities (C1) & 40.23 & \\
\hline Varicose vein (C2) & 43.29 & \\
\hline Edema (C3) & 45.57 & $<0.05$ \\
\hline Pigmentation (C4) & 53.09 & \\
\hline Healed Venous Ulcer (C5) & 45.33 & \\
\hline Active Venous Ulcer (C6) & 45.50 & \\
\hline
\end{tabular}

Comparing mean GSV diameter at the level of knee between age $\geq 45$ years and $<45$ years, BMI $\geq 30$ and $<30$ and gender did not show statistical significant difference. Mean GSV diameter in patients with duration of symptoms more than five years was significantly higher than that of less than five years $(p<0.01)$. (Table 4$)$

Table 4. Mean GSV diameter at the level of knee in two groups of age and two groups of duration of symptoms

\begin{tabular}{|c|c|c|c|}
\hline Variables & Categories & $\begin{array}{l}\text { Mean GSV diameter } \\
\text { at knee level }(\mathrm{mm})\end{array}$ & P value \\
\hline \multirow[t]{2}{*}{ Age } & $\geq 45$ Years & 6.89 & \multirow[t]{2}{*}{0.187} \\
\hline & Less than 45 Years & 6.18 & \\
\hline \multirow{2}{*}{$\begin{array}{l}\text { Duration of } \\
\text { symptoms }\end{array}$} & $>5$ Years & 7.63 & \multirow[t]{2}{*}{$<0.01$} \\
\hline & $<5$ Years & 5.84 & \\
\hline \multirow[t]{2}{*}{$\mathrm{BMI}\left(\mathrm{kg} / \mathrm{m}^{2}\right)$} & $\geq 30$ & 7.51 & \multirow[t]{2}{*}{0.153} \\
\hline & Less than 30 & 6.41 & \\
\hline \multirow[t]{2}{*}{ Gender } & Male & 6.62 & \multirow[t]{2}{*}{0.808} \\
\hline & Female & 6.48 & \\
\hline
\end{tabular}

Table 5. Mean SSV diameter at the level of knee in two groups of age and two groups of duration of symptoms

\begin{tabular}{|l|lll|}
\hline Variables & Categories & $\begin{array}{l}\text { Mean SSV diameter } \\
\text { at knee level(mm) }\end{array}$ & P value \\
\hline Age & $\geq 45$ Years & 8.78 & $<0.05$ \\
\hline $\begin{array}{l}\text { Duration of } \\
\text { symptoms }\end{array}$ & $>5$ Years than 45 Years & 7.16 & 0.760 \\
\hline BMI $\left(\mathrm{kg} / \mathrm{m}^{2}\right)$ & $\mathbf{2}$ Years & 8.14 & \\
\hline & Less than 30 & 7.89 & 0.890 \\
\hline Gender & Male & 8.16 & \\
\hline & Female & 7.86 & 0.764 \\
\hline
\end{tabular}

Table 6. Mean BMI in different clinical appearance (C) of CEAP Classification

\begin{tabular}{|lll|}
\hline Clinical Appearance(C) & Mean BMI & P value \\
\hline Varicosities (C1) & 26.95 & \\
\hline Varicose vein (C2) & 25.28 & \\
\hline Edema (C3) & 24.34 & 0.7 \\
\hline Pigmentation (C4) & 24.84 & \\
\hline Healed Venous Ulcer (C5) & 25.72 & \\
\hline Active Venous Ulcer (C6) & 24.14 & \\
\hline
\end{tabular}

Comparing mean SSV diameter at the level of knee in different groups of duration of symptoms, BMI and gender did not show statistically significant difference. Mean SSV diameter was found significantly higher in age more than 45 compared to less than 45 years group. (table 7)

There was no statistically significant difference between mean BMI of different $\mathrm{C}$ stages.

\section{DISCUSSION}

This study was designed to investigate the influence of $\mathrm{BMI}$, Age and Gender on stages of varicose vein. Prominent veins and feeling of heaviness in the affected limb were found to be most common presenting symptoms among our patients. Majority of the patients in our study belonged to C2 stage of CEAP Classification followed by C4 stage. Most of the patients had Great saphenous vein territory involvement $(77 \%)$ in this study. Our finding is similar to the findings observed in a study by Mendoza $\mathrm{E}$ which has shown that great saphenous vein is involved in majority of the cases. ${ }^{13}$

The average BMI of patients in this study was $25.42 \pm 4.42$ $\mathrm{kg} / \mathrm{m}^{2}$. Difference between the mean BMI among male and female patients was not statistically significant in this study ( $p>0.05$ ). No significant correlation between BMI and progression in Clinical staging of Varicose vein according to CEAP classification ( $p>0.05$ ) was noted in our study. However there are studies that had shown that the CEAP $C$ 
categories of CVD were significantly related to overweight and obesity. ${ }^{14}$ Small sample size of our study could be the cause for the inability to show significant relationship between BMI with $\mathrm{C}$ categories of CEAP classification.

In our study, mean age was highest in C4 stage (53.09 years). Significant correlation was found between increasing age and progression in Clinical staging of Varicose vein according to CEAP classification $(p<0.05)$ in our study. Our study has supported the fact that age is a well-known risk factor for the development of varicose vein and chronic venous disease as shown by studies. ${ }^{15,16}$ No significant difference was noted among male and female population of our study group.

On evaluating the mean GSV diameter at the level of knee in those limbs with varicose vein involving GSV territory, it showed significant correlation between mean GSV diameter at the level of knee in patients with duration of symptoms for more than 5 years $(p<0.05)$. Karmacharya et al. recommended having cutoff value for GSV at the level of the femoral condyle as more than $5 \mathrm{~mm}$ to predict SFJ incompetence and varicose vein with good sensitivity and specificity. ${ }^{17}$ In our study, mean GSV diameter was $7.63 \mathrm{~mm}$ in patients with symptoms for more than 5 years duration. However no statistical significance could be established between mean GSV diameter at the level of knee with age, sex and BMI ( $p>0.05)$ in our study. Similarly, no statistically significance was found between SSV diameter with age, sex, duration of symptoms and BMI in those limbs with SSV involvement $(p>0.05)$.

In our study, the male:female ratio was 1.4:1 showing male preponderance. This finding is contradictory to other prevalence studies which have shown this disease as more common in female compared to male. This difference can be due to better access to healthcare facility of male population as compared to female population in our community. The prevalence of varicose vein has been estimated to be higher in women with $25-33 \%$ compared to men with $10-20 \% .{ }^{18}$ However, In a study done at Edinburgh, prevalence however has been found more in men compared to women which is similar to our findings. ${ }^{6}$

\section{CONCLUSION}

This study showed that the Clinical Staging (C) of CEAP classification of varicose vein is significantly related to increasing age of the patient. The mean diameter of GSV at the level of knee is significantly related to the duration of symptoms. However, the influence of BMI and gender on stages of varicose vein could not be established. Studies with larger sample size would be required to study the influence of $\mathrm{BMI}$ and gender on the stages of varicose vein in general population in our part of world.

\section{REFERENCES}

1. Kurz X, Lamping DL, Kahn SR, Baccaglini U, Zuccarelli F, Spreafico G et al. Do varicose veins affect quality of life? Results of an international population-based study. J Vasc Surg. 2001;34:641-8.

2. Smith JJ, Garratt AM, Guest M, Greenhalgh RM, Davies AH. Evaluating and improving health-related quality of life in patients with varicose veins. J Vasc Surg. 1999;30:710-9.

3. Mooney WR. The fundamentals of phlebology: Venous disease for clinicians. Can Fam Physician. 2008;54(9):1289.

4. Nazmiye SK, Tulin UK, Turgay F, Hasan FK. Potential Risk Factors for Varicose Veins with Superficial Venous Reflux. International journal of vascular medicine. 2014. ID 531689:1-6.

5. Robertson L, Evans C, Fowkes FG. Epidemiology of chronic venous disease. Phlebology. 2008;23:103-11.

6. Evans CJ, Fowkes FGR, Ruckley CV, Lee AJ. Prevalence of varicose veins and chronic venous insufficiency in men and women in the general population: Edinburgh Vein Study. J Epidemiol Community Health. 1999;53:149-53.

7. Fowkes FG, Evans CJ, Lee AJ. Prevalence and risk factors of chronic venous insufficiency. Angiology. 2001; 52: S5-15.

8. Musil D, Kaletova M, Herman J. Age, body mass index and severity of primary chronic venous disease. Biomed Pap Med FacUnivPalacky Olomouc Czech Repub. 2011; 155 (4):367-71.

9. Beebe-Dimmer JL, Pfeifer JR, Engle JS, Schottenfeld D. The epidemiology of chronic venous insufficiency and varicose veins. Ann Epidemiol. 2005;15(3):175-84.

10. Seidel AC, Campos MB, Campos RB, Harada DS, Rossi RM, Junior PC, et al. Associations between symptoms and varicose veins and great saphenous vein reflux seen on Doppler ultrasonography. J Vasc Bras. 2017;16(1):4-10.

11. Marston WA. Evaluation of varicose veins: what do the clinical signs and symptoms reveal about the underlying disease and need for intervention? SeminVasc Surg. 2010;23(2):78-4.

12. Labropoulos N, Leon Jr LR. Duplex evaluation of venous insufficiency. SeminVasc Surg. 2005;18:5-9.

13. Mendoza E, Blattler W, Amsler F. Great saphenous vein diameter at the saphenofemoral junction and proximal thigh as parameters of venous disease class. Eur J Vasc Endovasc Surg. 2013;45(1):76-83.

14. Vlajinac HD, Marinkovic JM, Maksimovic MZ, Matic PA, Radak DJ. Body Mass Index and Primary Chronic Venous Disease A Crosssectional Study. Eur J Vasc Endovasc Surg. 2012;45(3):293-8.

15. Carpentier PH, Maricq HR, Biro C, Poncot-Makinen CO, Franco A. Prevalence, risk factors and clinical patterns of chronic venous disorders of lower limbs: a population-based study in France. J Vasc Surg. 2004;40:650-9.

16. Chiesa R, Marone EM, Limoni C, Volonte M, Schaefer E, Petrini O. Chronic venous insufficiency in Italy: the 24-Cities-Cohort Study. Eur J Vasc Endovasc Surg. 2005;30:422-9.

17. Karmacharya RM, Shrestha BK, Shrestha B. Prediction of saphenofemoral junction incompetence by measurement of great saphenous vein size at the level of femoral condyle. Indian J Vasc Endovasc Surg. 2018;5:92-4.

18. Segiet OA, Brzozowa-Zasada M, Piecuch A, Dudek D, Reichman WE, Wojnicz R. Biomolecular mechanisms in varicose veins development. Ann Vasc Surg. 2015;29:377-84. 